\title{
Photoperiodic control of development and reproduction in Harmonia axyridis (Coleoptera: Coccinellidae)
}

\author{
SERGEY Ya. REZNIK and NinA P. VAGHINA
}

Zoological Institute, Russian Academy of Sciences, 199034 St. Petersburg, Russia; e-mail: sreznik@zin.ru

\begin{abstract}
Key words. Coccinellidae, Harmonia axyridis, photoperiod, development, maturation, diapause, phenology
\end{abstract}
\begin{abstract}
The effects of photoperiod on pre-imaginal development and reproductive maturation of adult females of the multicolored Asian lady beetle, Harmonia axyridis (Pallas) (Coleoptera: Coccinellidae), were investigated at $20^{\circ} \mathrm{C}$ and at photoperiods from $10 \mathrm{~L}$ : 14D to $18 \mathrm{~L}: 6 \mathrm{D}$. Experiments were conducted on a laboratory strain that originated from the Russian Far East. Larvae and adults were fed on the green peach aphid Myzus persicae. Under short day conditions the pre-imaginal development was faster than under long day conditions. The acceleration of pre-imaginal development occurred when day length was shorter than $16 \mathrm{~h}$ and the threshold day length was ca $14 \mathrm{~h}$. The rate of reproductive maturation of adult females, in contrast, was twice as high under long day conditions, with the threshold between 14L : 10D and 12L : 12D, although even under short day conditions ca $10 \%$ of the females show a tendency to mature more quickly. This difference between the thresholds of these two photoperiodic reactions indicates they are relatively independent of one another.
\end{abstract}

\section{INTRODUCTION}

Day length can influence insect development and reproduction in many ways. The regulation of diapause is usually a clear-cut "yes or no" reaction with an evident adaptive significance. Various quantitative responses (the influence of photoperiod on the rate of growth and development, female fecundity, etc.), however, are often weak and ambiguous, their ecological role is not always clear and may be merely side effects of other "main" reactions or physiological phenomena having no ecological importance. One of the methods used to distinguish between a side effect and a relatively independent reaction is to compare the patterns and, specifically, the thresholds of the two reactions. Significant differences between patterns and thresholds of two reactions would indicate their relative independence. However, such studies are rarely conducted (Zaslavski, 1988; Denlinger, 2002; Saunders, 2002; Musolin et al., 2004; Lopatina et al., 2007; Saunders, 2010). In particular, although photoperiodic responses are reported for many species of Coccinellidae (Hodek \& Honěk, 1996, see Discussion for more references) in only a few are the influences of day length on the rate of the pre-imaginal development and the rate of reproductive maturation of adult females (or diapause induction) investigated over a range of photoperiods.

It is well known (Voronin, 1965; Sakurai et al., 1988; Ongagna \& Iperti, 1994; Hodek \& Honěk, 1996, Iperti \& Bertrand, 2001; Koch, 2003; Adriaens et al., 2008; Berkvens et al., 2008, 2010) that the multicolored Asian lady beetle Harmonia axyridis (Pallas) (Coleoptera: Coccinellidae) only overwinters in the adult stage. Thus, from an ecological point of view two predictions can be made. First, short days indicating the approach of winter should speed up pre-imaginal development in order to increase the proportion of individuals that reach the adult stage, but inhibit reproductive maturation of adult females and so accelerate diapause induction and avoid the production of progeny that will not reach the adult stage. Second, the day length threshold of the photoperiodic response inducing diapause should be shorter than that determining the rate of development: in autumn pre-imaginal development should accelerate before diapause is induced.

This study has also a practical aim: $H$. axyridis has been widely used for the biological control of aphids in the field and in greenhouses (Koch, 2003; Roy \& Wajnberg, 2008), but recently this predaceous coccinellid has attracted attention because of its unexpected ability to invade natural ecosystems and is now also considered to be an alien invader (Koch \& Galvan, 2008; Roy \& Wajnberg, 2008; Soares et al., 2008). The photoperiodic reactions of $H$. axyridis have been studied, but mostly to determine the optimal methods for mass rearing and storage, for example, authors (e.g. Ongagna \& Iperti, 1994) have compared only two photoperiodic regimes: a diapause-inducing short day and diapause-averting long day. In other experimental studies (Sakurai et al., 1988; Berkvens et al., 2008) only two contrasting photoperiods were used. However, an investigation of the total pattern of photoperiodic responses of an insect species and in particular the estimates of the threshold day lengths can be very important for predicting its phenology and potential geographic distribution, which for this coccinellid are matters of primary concern (Labrie et al., 2006; Adriaens et al., 2008; Brown et al., 2008; Koch \& Galvan, 2008; Poutsma et al., 2008; Van Lenteren et al., 2008). Moreover, the recently studied populations of $H$. axyridis originated from Japan (Sakurai et al., 1988) and Europe (Ongagna \& Iperti, 1994; Berkvens et al., 2008), and as this species is very variable (Soares et al., 2001; Lombaert et al., 2008; Berkvens et al., 2008, 2010) it would be interesting to investigate a population that originated from 


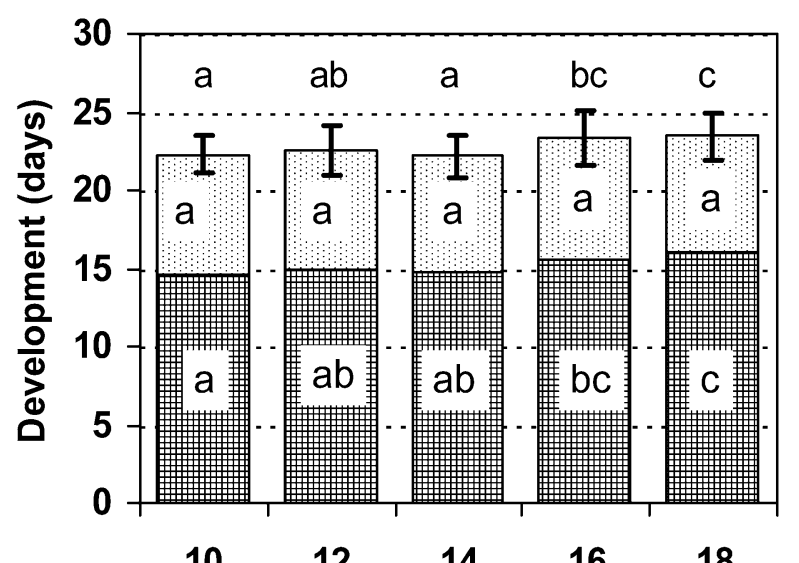

10
$1214 \quad 16$
18

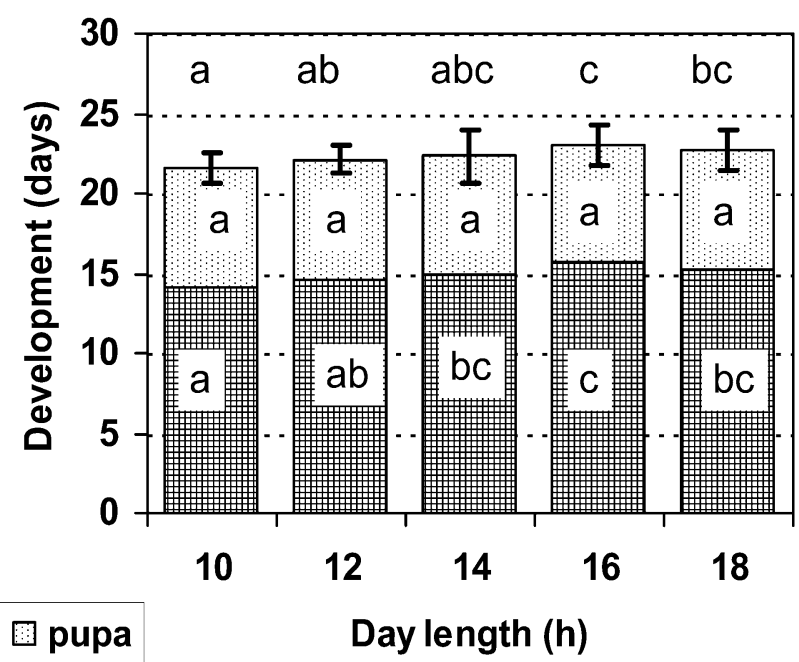

Fig. 1. Influence of photoperiod on the duration of pre-imaginal development of Harmonia axyridis. A - males, B - females. Means of the duration of larval and of pupal development and SDs for the total duration of pre-imaginal development are shown. Values with different letters in the same row are significantly different, letters above bars refer to the total duration of pre-imaginal development $(\mathrm{p}<0.05$, the Tukey HSD test).

some other region. The Russian Far East in this context seems to be particularly interesting as it lies at the same latitude as the earlier studied SE of France (Ongagna \& Iperti 1994; Iperti \& Bertrand, 2001; Berkvens et al., 2008) and thus has the same dynamics of natural day length, but is characterized by colder autumns and consequently the necessity for diapause to be induced earlier (see Discussion of the data). In addition, the Russian Far East is the northern border of the wide natural geographical range of $H$. axyridis (Adriaens et al., 2008; Brown et al., 2008; Lombaert et al., 2010) and the expectation is that these populations will show an earlier induction of winter diapause. Thus, the aim of the present work was to study, over a range of day lengths, the photoperiodic control of pre-imaginal development and reproductive maturation of adult females of a laboratory population of $H$. axyridis that originated from the Russian Far East.

\section{MATERIAL AND METHODS}

The experiment was conducted in 2009-2010 with a laboratory line of $H$. axyridis that originated from insects collected in 2004 in the Kedrovaya Pad' nature reserve (Khasanskiy region, Primorskiy territory of Russia) and then reared for 25-30 generations under constant conditions: $25^{\circ} \mathrm{C}, 18 \mathrm{~L}: 6 \mathrm{D}$, and fed on the green peach aphid, Myzus persicae (Sulz.) (Homoptera, Aphidae), reared on broad bean, Vicia faba L. plants. The strain studied (same as the original natural population) consisted predominantly ( $>95 \%$ ) of the non-melanic (f. succinea) morph. The data for the very few adult individuals in the experiment that were melanic were excluded from the statistical analysis.

To start the test, a group of similar-aged first instar larvae was randomly distributed between five photoperiodic regimes (L : D $=10: 14,12: 12,14: 10,16: 8$ and $18: 6$ ). The experiments were conducted in a thermostatic room at $20^{\circ} \mathrm{C}$. The larvae were kept individually in plastic Petri dishes (height: $15 \mathrm{~mm}$; diameter: $90 \mathrm{~mm}$ ). Aphids were provided daily in excess on bean seedlings. Pupation and adult emergence were recorded daily at the same time (4-6 h after lights-on). Newly emerged adults were sexed and kept in pairs under the same conditions as their pre-imaginal stages (males from the main laboratory strain were used if necessary). To determine the pre-oviposition period, each Petri dish was checked daily for eggs, also 4-6 h after lights-on. Thus, the duration of pre-imaginal development and the duration of reproductive maturation of adult females were recorded as the number of days from egg hatch to adult eclosion and adult eclosion to the laying of the first egg, respectively.

Development of 70-80 individuals and maturation of 25-35 females were studied at each of 5 photoperiods. The distributions of the durations of larval, pupal and total pre-imaginal development were close to normal and these data were analyzed using ANOVA; means and SDs were used as descriptive statistics, treatments were compared using the Tukey HSD test. The distribution of the duration of the pre-oviposition (reproductive maturation of adult females) period was skewed to the right (see Results). Therefore, this variable was log-transformed before ANOVA, medians and quartiles of untransformed data were used as descriptive statistics and the chi-square test was used to detect the differences in the distributions between treatments. Data on the survival to the adult stage were also compared using chi-square tests. To estimate the correlation between durations of pre-imaginal development and reproductive maturation of individual females, Spearman rank correlation coefficient was used. All the calculations were made using SYSTAT.

\section{RESULTS}

\section{Pre-imaginal development}

The average survival to the adult stage was $85 \%$ and there were no significant differences between photoperiods. Two-factor ANOVA $(\mathrm{n}=379$, day length and sex were the two factors) revealed that the duration of larval development and the total duration of pre-imaginal development were significantly ( $\mathrm{p}<0.001$ ) dependent on photoperiod $(\mathrm{F}=12.4$ and $\mathrm{F}=11.9$, respectively), while the duration of pupal development was independent of day 


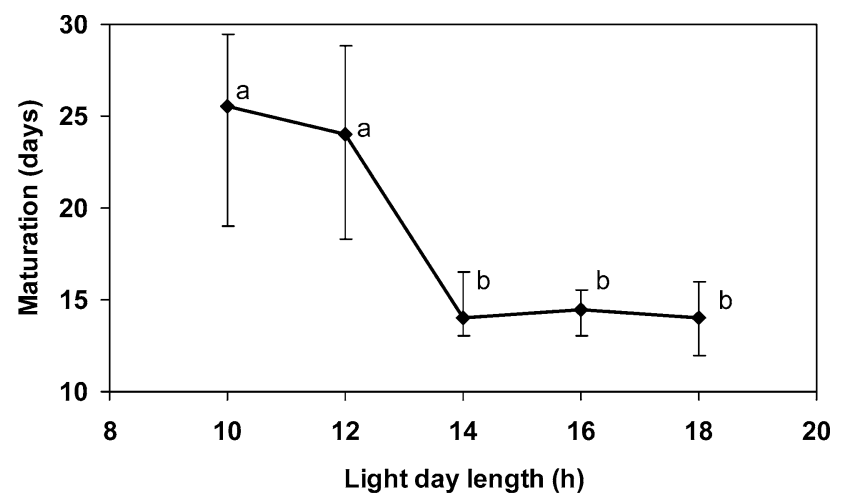

Fig. 2. Influence of photoperiod on the duration of reproductive maturation of adult females of Harmonia axyridis. Medians and quartiles are shown. Values with different letters are significantly different $(p<0.05$, the Tukey HSD test of logtransformed data).

length $(\mathrm{F}=1.9, \mathrm{p}=0.109)$. Obviously, short day length accelerated $H$. axyridis pre-imaginal development (Fig. $1)$.

In contrast to the sharp and clear-cut photoperiodic reaction determining the rate of reproductive maturation of adult females, the photoperiodic influence on the rate of $H$. axyridis pre-imaginal development was rather weak and almost gradual (comp. Figs 1 and 2). However, the threshold of this quantitative photoperiodic response can be at least roughly estimated as the day length causing the "intermediate" effect close to the average between those induced by "short" and "long" days. As seen in Fig. 1A, in males the duration of pre-imaginal development at $12 \mathrm{~L}$ : 12D and 14L : 10D was not significantly different from that at the shortest of the photoperiods used, 10L : 14D, while the data for $16 \mathrm{~L}: 8 \mathrm{D}$ and $18 \mathrm{~L}: 6 \mathrm{D}$ significantly differed from the three above mentioned treatments and were not significantly different from each other. In females (Fig. 1B), the results obtained at 10L : 14D and $12 \mathrm{~L}: 12 \mathrm{D}$ were significantly different from those

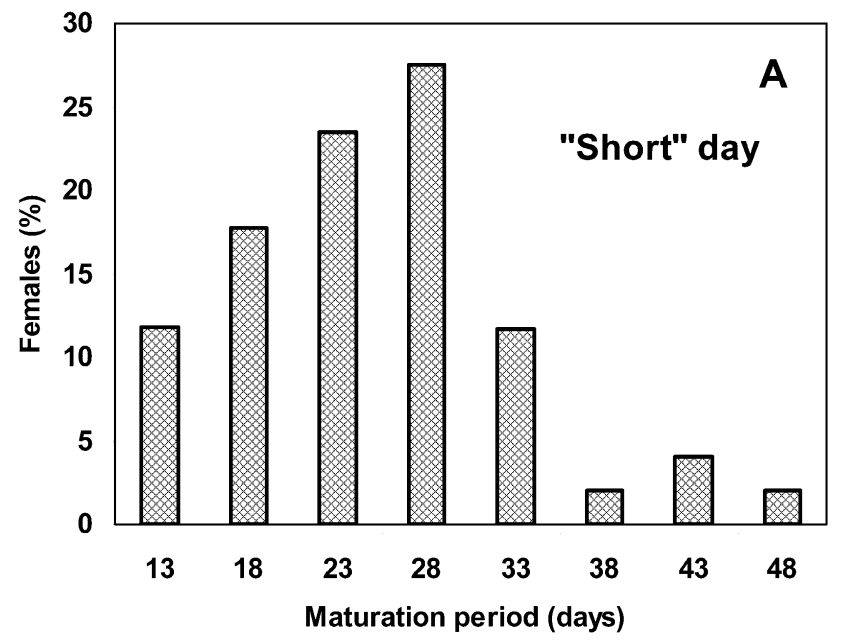

recorded in the treatment with the slowest development (16L : 8D), the data for $16 \mathrm{~L}: 8 \mathrm{D}$ and $18 \mathrm{~L}: 6 \mathrm{D}$ were significantly different from those recorded in the treatment with the fastest development (10L : 14D), while at 14L : $10 \mathrm{D}$ the duration of pre-imaginal development was intermediate. In combination, these results suggest that the acceleration of pre-imaginal development occurs when day length was shorter than $16 \mathrm{~h}$, while the threshold day length was ca $14 \mathrm{~h}$.

Gender significantly $(\mathrm{F}=7.5, \mathrm{p}=0.006)$ influenced the total duration of pre-imaginal development, although its influence on the duration of larval and pupal development was marginally insignificant $(\mathrm{F}=3.6, \mathrm{p}=0.059$ and $\mathrm{F}=$ $3.8, \mathrm{p}=0.052$, respectively). Males of the population of $H$. axyridis studied developed slightly but significantly slower than females, the mean difference in the duration of pre-imaginal development was 0.4 day or less than $2 \%$ of the total. Two-factor ANOVA of the total data $(\mathrm{n}=$ 379) showed that the interaction of photoperiod with sex in their influence on the duration of pre-imaginal development was not significant $(\mathrm{F}=1.4, \mathrm{p}=0.24)$.

\section{Reproductive maturation of adult females}

The duration of the pre-oviposition (reproductive maturation) period of $H$. axyridis females was markedly dependent on day length $(\mathrm{n}=150, \mathrm{~F}=34.3, \mathrm{p}<0.001$, ANOVA of log-transformed data). As seen in Fig. 2 a typical long-day photoperiodic response was revealed. Noteworthy, in contrast to pre-imaginal development, the rate of reproductive maturation of adult females at $14 \mathrm{~L}$ : $10 \mathrm{D}$ was practically equal to that at longer photoperiods and markedly different from the results obtained at $12 \mathrm{~L}$ : $12 \mathrm{D}$ and $10 \mathrm{~L}: 14 \mathrm{D}$. Obviously, the decrease in the rate of reproductive maturation of adult females occurred when day length was shorter than $14 \mathrm{~h}$, the threshold day length was ca $13 \mathrm{~h}$. However, the frequency distribution plots (comp. Figs 3a and 3b) clearly showed that more than $10 \%$ of the females that developed and matured under

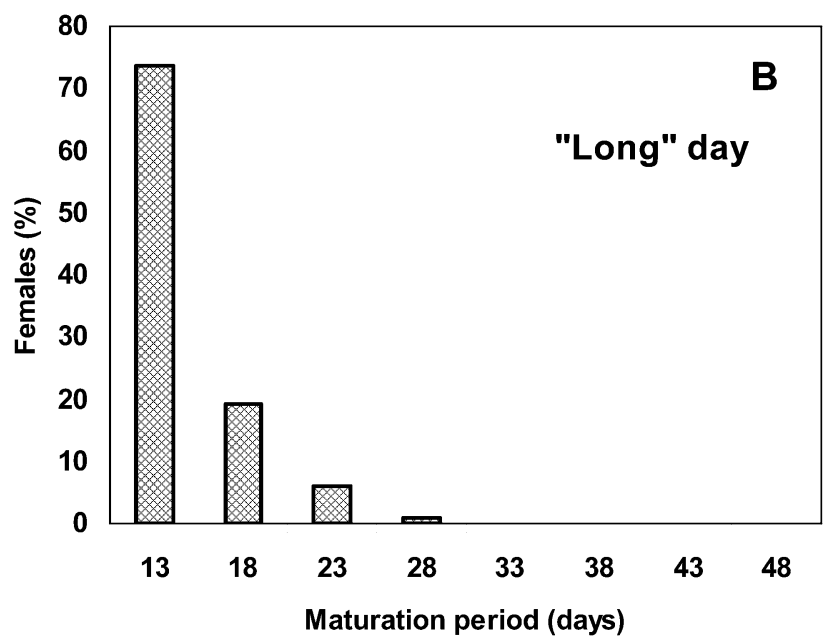

Fig. 3. The frequency distribution of the durations of reproductive maturation of adult females of Harmonia axyridis. Females are grouped in intervals of 5 days: 11-15, 16-20, etc days spent in reproductive maturation. Mid-points of intervals and percentage of females in each group are indicated. A - under "short" day conditions (10L : 14D and 12L : 12D); B - under "long" day conditions $(14 \mathrm{~L}: 10 \mathrm{D}, 16 \mathrm{~L}: 8 \mathrm{D}$, and $18 \mathrm{~L}: 6 \mathrm{D})$. 
"short" day conditions (10L : 14D and 12L : 12D) matured as fast as the majority of those that developed and matured under "long" day conditions (14L : 10D, $16 \mathrm{~L}: 8 \mathrm{D}$, and $18 \mathrm{~L}: 6 \mathrm{D})$.

The Spearman rank correlation between durations of pre-imaginal development and reproductive maturation of individual females for the total pooled data was significantly negative $(\mathrm{r}=-0.32, \mathrm{n}=150, \mathrm{p}<0.001)$, while the separate analyses of the results obtained at each photoperiod did not reveal any significant correlations.

\section{DISCUSSION}

\section{Pre-imaginal development}

Diapause-inducing short day conditions sometimes (but by no means always) accelerates the development of the stages preceding diapause, thus increasing the percentage of the population that has time to prepare for overwintering (Zaslavski, 1988; Saunders, 2002; Lopatina et al., 2007). The data presented accords with this generalization, although in other coccinellid species the rate of development is independent of photoperiod (McMullen, 1967; Hodek \& Honěk, 1996). Ongagna \& Iperti (1994) state that short day conditions slow down $H$. axyridis development, but Table 1 in this paper indicates that at day lengths of 10.5-11.5 h larval development was faster than at day lengths of 14.5-16 h. Berkvens et al. (2008) also record that the duration of pre-imaginal development of individuals of a laboratory strain of $H$. axyridis reared at $12 \mathrm{~L}: 12 \mathrm{D}$ is shorter than at $16 \mathrm{~L}: 8 \mathrm{D}$, although larvae from a "natural" strain, cultured in laboratory for only 4 generations, in contrast, developed faster under long day conditions. Such a high intra-specific variability of various morphological and physiological parameters is often recorded for $H$. axyridis (Soares et al., 2001; Lombaert et al., 2008; Berkvens et al., 2008, 2010). In contrast to the duration of the larval stage, that of the pupal stage is independent of day length, which is typical of other insect species except those with a pupal diapause (Zaslavski, 1988; Saunders, 2002).

The relative acceleration of the pre-imaginal development revealed in this study was rather small: the maximal differences between the means for different photoperiods were 1.2 and 1.4 days (for males and females, respectively) constituting 5-6\% of the total duration of development. Somewhat higher (although not unidirectional) differences, 2-3 days or ca $10 \%$ of the total duration of development, are recorded for other populations of $H$. axyridis by Berkvens et al. (2008). Interestingly, although the influence of photoperiod on the duration of preimaginal development in laboratory and natural populations were opposite, the photoperiodic reactions determining the rate of reproductive maturation have the same trend (comp. Figs 1 and 2 in the cited paper), which can be considered as further evidence of the relative independence of the two photoperiodic responses. In the experiments conducted by Ongagna \& Iperti (1994) the difference in rates of development among photoperiods were as much as 6 days or $20 \%$ of the total and resulted from the application of increasing vs. decreasing day lengths, which often cause stronger reactions than those induced by constant photoperiods (Zaslavski, 1988; Saunders, 2002). In addition, food can markedly influence the duration of pre-imaginal development (Hodek \& Honěk, 1996; Berkvens et al., 2008; Reznik, 2010), which also makes the comparison of results obtained by different authors difficult. Obviously, the influence of photoperiod on the rate of pre-imaginal development in $H$. axyridis is extremely variable as is its influence on many other parameters of this coccinellid (Soares et al., 2001; Lombaert et al., 2008; Berkvens et al., 2008, 2010).

In similar experiments conducted with other insect species, the influence of photoperiod on the duration of preimaginal development is also very variable. For example, in a recent detailed study of the influence of photoperiod on the pre-imaginal development of different populations of the linden bug, Pyrrhocoris apterus (Heteroptera: Pyrrhocoridae), the differences between the results obtained at short and long days varied, depending on temperature, from practically zero to more than $20 \%$ (Lopatina et al., 2007), while in similar experiments conducted with other representative of the same order, Orius strigicollis (Poppius) (Heteroptera: Anthocoridae), the maximum difference between the duration of pre-imaginal development under short and long days did not exceed $10 \%$ of the total (Musolin et al., 2004). Generally, the effect of photoperiod on the duration of insect development can vary from slight changes to a sharp increase, although in the last case not protracted development but diapause induction can occur (Tauber et al., 1986; Zaslavski, 1988; Saunders, 2002). Naturally, in each particular case the possibility of photoperiod induced acceleration of development is limited by basic physiological parameters. However, even a slight increase in the rate of development can result in an increase in the proportion of adults that have time to prepare for wintering, particularly when accelerated development is followed by the delayed maturation of adults. The close co-ordination in the above effects and the dynamics of the day length at the population's origin suggest that the photoperiodic responses recorded are controlled by natural selection and thus have some adaptive value.

Protandry (a tendency for males to emerge before females through the shortening of the developmental time) is typical of certain insect taxa (Bulmer, 1983). However, in this study, the duration of pre-imaginal development in males was the same or slightly longer than that of females. Similar results are recorded for European populations of $H$. axyridis (Berkvens et al., 2008), although the differences were so small that they were not statistically evaluated by the authors.

\section{Reproductive maturation of adult females}

In many insect species, facultative reproductive diapause is known to be regulated by photoperiod (Tauber et al., 1986; Zaslavski, 1988; Denlinger, 2002; Saunders, 2002, 2010). This is also the case for several predatory coccinellids (Zaslavski \& Bogdanova, 1965; McMullen, 1967; Zaslavski, 1970; Hodek \& Iperti, 1983; Obrycki et al., 1983; Okuda \& Hodek, 1994; Hodek \& Honěk, 1996; Hodek \& Okuda, 1997) and particularly H. axyridis 
(Voronin, 1965; Sakurai et al., 1988; Ongagna \& Iperti, 1994; Berkvens et al., 2008). The results presented revealed a typical simple long-day photoperiodic response similar to that recorded e.g. in Adalia bipunctata L. (Obrycki et al., 1983) and Chilocorus species (Zaslavski \& Bogdanova, 1965, Zaslavski, 1970).

It is important that the short day did not fully prevent oviposition: it was only delayed by various intervals. Furthermore, the data clearly showed that some of the females that developed and were kept under short day conditions, had pre-oviposition periods that were as short as those of females that developed and were kept under long day conditions. Taking into consideration the high variability of the results, it is quite probable that a small fraction of fast maturing females of $H$. axyridis was also present in earlier studies (Ongagna \& Iperti, 1994; Berkvens et al., 2008). The "fast" and "slow" fractions of autumnal adults are recorded in other Coccinellidae (Hodek \& Iperti, 1983; Hodek \& Honěk, 1996). In further investigations on this subject, it would be important to analyze not only the average duration of the preoviposition period, but also its distribution.

Finally, a comparison of Figs 1 and 2 shows that not only the trends in the two photoperiodic reactions differ, with short day conditions speeding up pre-imaginal development and slowing down reproductive maturation of adult females, but also the threshold day length for inducing diapause is shorter than that determining the rate of development. In autumn, the increase in the preimaginal developmental rate occurs when day length is shorter than $16 \mathrm{~h}$ and the threshold day length for this is ca $14 \mathrm{~h}$, whereas the reproductive maturation of adult females slows down later and the threshold for this lies between 14 and $12 \mathrm{~h}$. As was noted in the Introduction, the adaptive significance of this difference is clear: in autumn, they should develop quickly as the time for them to enter diapause is approaching. Thus, the data presented suggest that the influence of day length on the rate of larval development is a relatively independent and ecologically important response rather than a physiological phenomenon or a side effect.

The results of the correlation analysis of the pooled data for individual females indicate that the duration of pre-imaginal development was negatively correlated with the duration of reproductive maturation, which is to be expected from the opposite trends in the effect of photoperiod on these two processes, while the separate analyses of the results at each photoperiod did not reveal any significant correlations.

In the context of $H$. axyridis phenology, the data presented suggest that a sharp increase in the tendency to delay female maturation can be expected when the day length is $13 \mathrm{~h}$ or shorter. In the southern part of the Russian Far East this occurs at the end of August. Indeed, short days "merely double the duration of the preoviposition period" (Sakurai et al., 1988), but in combination with decreasing temperature and shortage of prey, the delay in maturation can result in a "real" long winter diapause. Moreover, unlike shortage of prey and temperature, day length is the single factor that can induce reproductive diapause well in advance of the onset of adverse conditions (Tauber et al., 1986; Zaslavski, 1988; Denlinger, 2002; Saunders, 2002, 2010). The results of earlier field studies conducted in the Russian Far East agree with the experimental data presented, although Voronin (1965) report a somewhat longer threshold day length of $14 \mathrm{~h} 30 \mathrm{~m}$. This close agreement between the results presented and data obtained in seminatural conditions for insects from natural populations provide good evidence that in spite of relatively longterm laboratory rearing, the strain used still shows the same photoperiodic response as the initial population.

As noted above, the threshold day length has not been determined for European populations. Iperti \& Bertrand (2001) note that "Decreasing temperature $\left(<22^{\circ} \mathrm{C}\right)$ and photoperiod $(<14: 40)$ acting on the pre-imaginal stages induce imaginal diapause". However, in another publication (Ongagna \& Iperti 1994), it is stated that at $20^{\circ} \mathrm{C}$ and a photophase of more than $12 \mathrm{~h}$ females remained active, and this estimate of the critical day length seems to be much more plausible as it is also reported for $H$. axyridis populations in SE France, where diapause was induced in December (Ongagna \& Iperti, 1994; Iperti \& Bertrand, 2001). It is known (Adriaens et al., 2008; Brown et al., 2008; Lombaert et al., 2010) that West European invasive populations of $H$. axyridis originated from SE Asia (directly and/or via Eastern North America). Their fast invasion of Europe suggests that they are well adapted to the new environment. The $2 \mathrm{~h}$ difference in the threshold photoperiods of populations in SE France and the southern part of the Russian Far East can be easily explained: although the two regions are at the same latitude $\left(\mathrm{ca} 43^{\circ} \mathrm{N}\right)$ the latter is characterized by much colder autumns. In SE France, the average temperatures in September, October and November are $20^{\circ}, 15^{\circ}$ and $12^{\circ} \mathrm{C}$, while in the Russian Far East they are $15^{\circ}, 10^{\circ}$ and $0^{\circ} \mathrm{C}$, respectively (data from http://www.weatheronline.co.uk). The European populations of $H$. axyridis are now spreading into central and northwestern Europe (Adriaens et al., 2008; Brown et al., 2008; Poutsma et al., 2008; Van Lenteren et al., 2008; Barševskis, 2009; Berkvens et al., 2010). That relatively long day length induces diapause revealed by this study indicate that if unintentionally introduced the Far Eastern population would be able to colonize areas much further north than other strains.

ACKNOWLEDGEMENTS. We are deeply grateful to V.P. Semyanov for providing the possibility to use the laboratory line of $H$. axyridis and to L.S. Ramenskaya for assistance in conducting the experiments. We thank the anonymous reviewers for valuable critical comments and suggestions. This study was partly supported by the Program of the Department of Biological Sciences of RAS "Biological resources of Russia: estimation and fundamental bases of monitoring" and by the State contract "Unique collection funds of the Zoological Institute RAS” (UFK ZIN, n. 2-2.20). 


\section{REFERENCES}

Adriaens T., San Martin G. \& Maes D. 2008: Invasion history, habitat preferences and phenology of the invasive ladybird Harmonia axyridis in Belgium. BioControl 53: 69-88.

BARŠEvskis A. 2009: Multicoloured Asian lady beetle (Harmonia axyridis (Pallas, 1773)) (Coleoptera: Coccinellidae) for the first time in the fauna of Latvia. Baltic J. Coleopterol. 9: $135-38$.

Berkvens N., Bonte J., Berkvens D., Tirry L. \& De Clerce P. 2008: Influence of diet and photoperiod on development and reproduction of European populations of Harmonia axyridis (Pallas) (Coleoptera: Coccinellidae). BioControl 53: 211-221.

Berkvens N., Bale J.S., Berkvens D., Tirry L. \& De Clerce P. 2010: Cold tolerance of the harlequin ladybird Harmonia axyridis in Europe. J. Insect Physiol. 56: 438-444.

Brown P.M.J., Adriaens T., Bathon H., Cuppen J., Goldarazena A., Hägg T., Kenis M., Klausnitzer B.E.M., Kovář I., Loomans A.J.M., Majerus M.E.N., Nedved O., Pedersen J., Rabitsch W., Roy H.E., Ternois V., Zakharov I.A. \& Roy D.B. 2008: Harmonia axyridis in Europe: spread and distribution of a non-native coccinellid. BioControl 53: 5-21.

Bulmer M.G. 1983: Models for the evolution of protandry in insects. Theor. Pop. Biol. 23: 314-322.

Denlinger D.L. 2002: Regulation of diapause. Annu. Rev. Entomol. 47: 93-122.

Hodek I. \& HonĚK A. 1996: Ecology of Coccinellidae. Kluwer Academic Publishers, Dordrecht, 480 pp.

Hodek I. \& IPERTI G. 1983: Sensitivity to photoperiod in relation to diapause in Semiadalia undecimnotata females. Entomol. Exp. Appl. 34: 9-12.

Hodek I. \& Окида T. 1997: Regulation of adult diapause in Coccinella septempunctata septempunctata and C. septempunctata brucki from two regions of Japan (a minireview). Entomophaga 42: 139-144.

IPERTI G. \& Bertrand E. 2001: Hibernation of Harmonia axyridis (Coleoptera: Coccinellidae) in South-Eastern France. Acta Soc. Zool. Bohem. 65: 207-210.

KocH R.L. 2003: The multicoloured Asian lady beetle, Harmonia axyridis: a review of its biology, uses in biological control and non-target impacts. J. Insect Sci. 3: 1-16.

Koch R.L. \& Galvan T.L. 2008: Bad side of a good beetle: the North American experience with Harmonia axyridis. BioControl 53: 23-35.

Labrie G., Lucas E. \& Coderre D. 2006: Can developmental and behavioral characteristics of the multicolored Asian lady beetle Harmonia axyridis explain its invasive success? Biol. Invas. 8: 743-754.

Lombaert E., Malausa T., Devred R. \& Estoup A. 2008: Phenotypic variation in invasive and biocontrol populations of the harlequin ladybird, Harmonia axyridis. BioControl 53: 89-102.

Lombaert E., Guillemaud T., Cornuet J.-M., Malausa T., FACON B. \& Estoup A. 2010: Bridgehead effect in the worldwide invasion of the biocontrol harlequin ladybird. PLoS One 5(3): e9743. doi:10.1371/journal.pone.0009743

Lopatina E.B., Balashov S.V. \& Kipyatkov V.E. 2007: First demonstration of the influence of photoperiod on the thermal requirements for development in insects and in particular the linden-bug, Pyrrhocoris apterus (Heteroptera: Pyrrhocoridae). Eur. J. Entomol. 104: 23-31.

MCMulLEN R.D. 1967: The effects of photoperiod, temperature and food supply on rate of development and diapause in Coccinella novemnotata. Can. Entomol. 99: 578-586.
Musolin D.L., Tsytsulina K. \& Ito K. 2004: Photoperiodic and temperature control of reproductive diapause induction in the predatory bug Orius strigicollis (Heteroptera: Anthocoridae) and its implications for biological control. Biol. Contr. 31: 91-98

Obrycki J.J., Tauber M.J., Tauber C.A. \& Gollands B. 1983: Environmental control of the seasonal life cycle of Adalia bipunctata (Coleoptera: Coccinellidae). Environ. Entomol. 12: 416-421.

OKudA T. \& Hodek I. 1994: Diapause and photoperiodic response in Coccinella septempunctata brucki Mulsant (Coleoptera: Coccinellidae) in Hokkaido, Japan. Appl. Entomol. Zool. 29: 549-554.

Ongagna P. \& IPERTi G. 1994: Influence of temperature and photoperiod on Harmonia axyridis Pall. (Col., Coccinellidae): rapidly obtaining fecund adults or in dormancy. J. Appl. Entomol. 117: 314-317.

Poutsma J., Loomans A.J.M., Aukema B. \& Heijerman T. 2008: Predicting the potential geographical distribution of the harlequin ladybird, Harmonia axyridis, using the CLIMEX model. BioControl 53: 103-125.

REZNIK S.YA. 2010: On the effects of diet and photoperiod on Harmonia axyridis (Pallas) (Coleoptera, Coccinellidae) larval development. Entomol. Rev. 90: 411-414.

Roy H. \& WaJnBERG E. 2008: From biological control to invasion: the ladybird Harmonia axyridis as a model species. BioControl 53: 1-4.

Sakurai H., Takeda S. \& Kawai T. 1988: Diapause regulation in the lady beetle, Harmonia axyridis. In Niemczyk E. \& Dixon A.F.G. (eds): Ecology and Effectiveness of Aphidophaga. SPB Academic Publishing, The Hague, pp. 67-69.

SAUNDERS D.S. 2002: Insect Clocks. Elsevier, Amsterdam, 576 pp.

SAunders D.S. 2010: Photoperiodism in insects: Migration and diapause responses. In Nelson R.J., Denlinger D.L. \& Somers D.E. (eds): Photoperiodism: The Biological Calendar. Oxford University Press, New York, pp. 218-257.

Soares A.O., Coderre D. \& Schanderl H. 2001: Influence of phenotype on fitness parameters of Harmonia axyridis Pallas (Coleoptera: Coccinellidae). Eur. J. Entomol. 98: 287-293.

Soares A.O., Borges I., Borges P.A.V., Labrie G. \& Lucas E. 2008: Harmonia axyridis: what will stop the invader? BioControl 53: 127-145.

Tauber M.J., Tauber C.A. \& Masaki S. 1986: Seasonal Adaptations of Insects. Oxford University Press, New York, 411 pp.

VAn Lenteren J.C., LoOmans A.J.M., BABendreier D. \& Bigler F. 2008: Harmonia axyridis: an environmental risk assessment for Northwest Europe. BioControl 53: 37-54.

Voronin K.E. 1965: The peculiarities of the formation of overwintering population of the Far Eastern lady beetle, Harmonia axyridis Pall (Coleoptera, Coccinellidae), a predator of aphids. Proc. All-Union Institute of Plant Protection (Leningrad) 24: 228-233 [in Russian].

ZASLAVSKI V.A. 1970: Geographical races of Chilocorus bipustulatus L. (Coleoptera, Coccinellidae). I. Two types of photoperiodical reaction controlling the imaginal diapause in the northern race. Zool. Zh. 49: 1354-1365 [in Russian].

Zaslavski V.A. 1988: Insect Development: Photoperiodic and Temperature Control. Springer, New York, Berlin, 187 pp.

ZaslavSKI V.A. \& Bogdanova T.P. 1965: Peculiarities of the imaginal diapause in two Chilocorus species (Coleoptera, Coccinellidae). Trudy Zool. Inst. Akad. Nauk SSSR (Leningrad) 36: 89-95 [in Russian].

Received January 11, 2011; revised and accepted March 11, 2011 